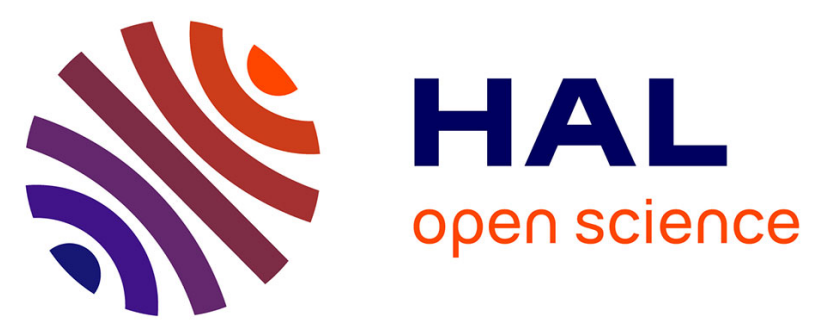

\title{
Contribution of the finite volume point dilution method for measurement of groundwater fluxes in a fractured aquifer
}

P. Jamin, Pascal Goderniaux, Olivier Bour, Tanguy Le Borgne, A. Englert, Laurent Longuevergne, S. Brouyère

\section{To cite this version:}

P. Jamin, Pascal Goderniaux, Olivier Bour, Tanguy Le Borgne, A. Englert, et al.. Contribution of the finite volume point dilution method for measurement of groundwater fluxes in a fractured aquifer. Journal of Contaminant Hydrology, 2015, 182, pp.244-255. 10.1016/j.jconhyd.2015.09.002 . insu01200777

\section{HAL Id: insu-01200777 https://hal-insu.archives-ouvertes.fr/insu-01200777}

Submitted on 17 Sep 2015

HAL is a multi-disciplinary open access archive for the deposit and dissemination of scientific research documents, whether they are published or not. The documents may come from teaching and research institutions in France or abroad, or from public or private research centers.
L'archive ouverte pluridisciplinaire HAL, est destinée au dépôt et à la diffusion de documents scientifiques de niveau recherche, publiés ou non, émanant des établissements d'enseignement et de recherche français ou étrangers, des laboratoires publics ou privés. 


\section{Contribution of the Finite Volume Point Dilution Method for measurement of}

\section{groundwater fluxes in a fractured aquifer.}

\section{P. Jamin ${ }^{1}$, P. Goderniaux ${ }^{2,3}$, O. Bour ${ }^{2}$, T. Le Borgne ${ }^{2}$, A Englert ${ }^{4}$, L. Longuevergne ${ }^{2}$ and S. Brouyère ${ }^{1}$}

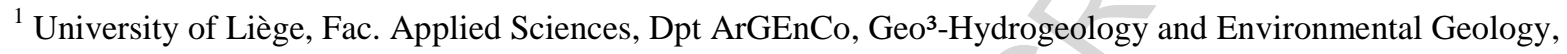
Building B52, 4000 Sart Tilman, Belgium. Serge.Brouyere@ulg.ac.be

${ }^{2}$ Géosciences Rennes (UMR CNRS 6118)-OSUR, University of Rennes 1, Rennes, France

${ }^{3}$ University of Mons, Department of Geology and Applied Geology

${ }^{4}$ Ruhr-Universität Bochum, Geology, Mineralogy and Geophysics, Germany.
} 


\section{Key words}

Finite Volume Point Dilution Method

Groundwater flux

Uncertainty analysis

Double packer

Single-well tracer test

Fractured aquifer. 


\section{Introduction}

Estimation of groundwater fluxes remains the basis of all hydrogeological study, from hydraulics characterization to the most advanced reactive transport modelling. Investigations on contaminant behavior, design of remediation systems, groundwater-surface water interactions or geothermal applications, all would benefits from a precise quantification of groundwater fluxes and their temporal and spatial variability. Groundwater fluxes are usually indirectly calculated with Darcy's law from piezometric gradient measurements and the estimation of hydraulic conductivity with pumping/slug tests. This simple method may be adequate for the estimation of general groundwater fluxes in homogeneous media but the resolution is generally low, leading to cumulated errors on spatial variability in heterogeneous context (Bright et al. 2002, Devlin and McElwee 2007).

Estimation of groundwater fluxes in fractured aquifer is a challenge given the heterogeneity that is induced by discrete fractures (Novakowski 2006). The characterization of fracture flow based on hydraulic pressure measurements can actually lead to misinterpretation about the role of the fracture in terms of flow path and solute transport. For example, a dead-end fracture subjected to pumping will respond in terms of hydraulic pressure variations even if no groundwater flow is occurring. Zha et al. (2014) recently emphasized that flux data used in hydraulic characterization of fractured media improve estimation of fracture patterns and hydraulic conductivity fields.

Therefore, tracer tests become essential tools because they allow studying the actual displacement of water. Classical tracer tests provide averaged information between two injection and recovery points. Alternative methods, such as point dilution tracer tests are promising to obtain a direct measurement of local groundwater fluxes or Darcy fluxes $\left(q_{D}\right)$ 
(Halevy et al. 1967, Klotz et al. 1979, Zlotnik and Zurbuchen 2003, Brainerd and Robbins 2004, Hatfield et al. 2004, Huang and Goltz 2005, Pitark et al. 2007, West and Odling 2007, Sale et al. 2007). Novakowski et al. (1995 and 2006) performed classical dilution tests between packers and pointed out two major issues. The first issue is related to the estimation of the actual mixing volume $\left(V_{w}\right)$, which has to be accurately known to interpret the dilution test. This mixing volume is difficult to calculate in case of dilution test performed between the packers because the test space is full of equipment (hoses, probes, mixing propellers ...) and may include zone of immobile water. Furthermore, the geometry of the borehole in front of the tested zone may not be perfectly cylindrical and part of the adjacent fractured medium may also be involved in the mixing processes. The second issue is that groundwater velocity changed during their experiments and disturbed the recording. The point dilution method (PDM) is actually a short time experiment that is constrained by both the maximum concentration that can be injected and the minimum concentration that can be measured in the well. The experiment stops when all the tracer has been eluted from the well, precluding continuous monitoring of groundwater fluxes.

The Finite Volume Point Dilution Method (FVPDM) (Brouyère 2003, Brouyère et al. 2008) allows overcoming those two issues and provides a quantification by a simultaneous and independent estimation of the mixing volume $\left(V_{w}\right)$ and Darcy's flux $\left(\mathrm{q}_{\mathrm{D}}\right)$ on experimental data. The duration of the test is not limited and can last as long as the experiment is maintained active by injecting tracer and monitoring its concentrations in the mixed water volume. Measurements of groundwater flux at a local scale, as achieved with this method, are complementary with more regional and indirect estimations from Darcy's law. The method was tested successfully in porous media (Brouyère et al. 2008, Goderniaux et al. 2010), but has never been experienced in fractured aquifers. 
In this context, the objectives of this paper are twofold: (1) test the method in a fractured geological context; and (2) compare the FVPDM with classical PDM on the same experimental site, hydraulic conditions, and experimental setup. The comparison investigates the relative precision of the two techniques on the measurement of groundwater fluxes and it provides guidelines for dilution experiments in fractured media. The contribution of the FVPDM for groundwater fluxes measurement in fractured aquifer is also discussed in terms of experimental setup.

A series of tracer dilution experiments were performed in the Ploemeur test site (Britany, France) on several fractured zones of an open well. For the first time, the FVPDM was used between a double packer system to investigate localized groundwater flows in discrete fractures. Successive experiments were carried out with different pumping rates applied at a nearby well, to investigate the largest range of possible groundwater flux measurements, and to study the consistency of results over this range. Classical PDM were also performed following each FVPDM experiment to compare the sensitivity and uncertainties of both methods. After a description of the methodology and the experimental setup, the results of the groundwater flux measurements are discussed along with uncertainties on the interpretation of the FVPDM and PDM. 


\section{Methodology}

\subsection{Point dilution techniques}

The aim of a single borehole dilution test is to perform a direct measurement of groundwater fluxes. Point dilution methods relate the concentration evolution of a tracer previously injected in a borehole as a function of the intensity of groundwater flow through the screen of the borehole. The result of such test is a groundwater flux, which depends on the hydraulic conditions within the geological formation and in the vicinity of the tested borehole (Drost $e t$ al. 1968, Hall 1996).Since the first use of PDM in 1916 reported by Halevy et al. (1967), many PDM configurations have been tested, including the experiments by Kaufmann and Todd (1962) and Novakowski et al. (1998, 2006), using inflatable packers to limit the vertical extension of the investigated zone. The tracer can be salt species, fluorescent dyes or radio isotopes (Koltz et al. 1979).

The Finite Volume Point Dilution Method (FVPDM) generalizes the PDM to more advanced tracer injection scenarios. The FVPDM is performed by continuously injecting a tracer fluid into a well and monitoring the evolution of the tracer concentration into the same well. During all the experiment, the water column within this well is mixed to ensure a homogeneous repartition of the tracer mass. This method is originally based on a mathematical and a numerical model of tracer injection into a well, considered as a mass balance of the injection of tracer fluid and transit groundwater flow passing through the well screen (Brouyère 2003). An analytical solution obtained from this model (Equation 1) was further applied as a single well tracer technique, enabling an accurate estimation of Darcy fluxes (Brouyère et al., 2008).

$C_{w}(t)=\frac{Q_{\text {in }} \times C_{\text {in }}-\left(Q_{\text {in }} \times C_{\text {in }}-Q_{\text {out }} \times C_{w, 0}\right) \times e^{-\frac{Q_{\text {out }}}{V_{w}} \times\left(t-t_{0}\right)}}{Q_{\text {out }}}$ with $Q_{\text {out }}=Q_{\text {in }}+Q_{t}^{\text {in }}$ 
The tracer concentration within the well $C_{w}(t)\left[\mathrm{ML}^{-3}\right]$ can be calculated at each time $t[\mathrm{~T}]$ using the parameters defined by the experimental setup $C_{i n}$ [ML-3] the tracer concentration in the injection solution, $C_{w, 0}\left[\mathrm{ML}^{-3}\right]$ the tracer concentration within the well at initial time $t_{0}$ $[\mathrm{T}], Q_{\text {in }}\left[\mathrm{L}^{3} \mathrm{~T}^{-1}\right]$ the tracer fluid injection flow rate and $V_{w}\left[\mathrm{~L}^{3}\right]$ the volume of water in the injection well, assumed to be constant. $Q_{\text {out }}\left[\mathrm{L}^{3} \mathrm{~T}^{-1}\right]$, the flow rate leaving the well through the screen, carrying tracer at concentration $C_{w}$ and representing the sum of Qin and $Q_{t}^{i n}\left[\mathrm{~L}^{3} \mathrm{~T}^{-1}\right]$ the transit flow rate intercepted by the well screen during tracer fluid injection at a rate $Q_{i n}$. When $Q_{\text {in }}=0, Q_{t}^{\text {in }}=Q_{\text {out }}$ and can be defined as $Q_{t}$, the transit flow rate under ambient conditions. $Q_{t}$ is directly related to the Darcy's flux $v\left[\mathrm{~L} \mathrm{~T}^{-1}\right]$ by the flow section $A\left[\mathrm{~L}^{2}\right]$ perpendicular to the groundwater flow. This area corresponds for fractured aquifer to the aperture of the fractures multiplied by the diameter of the borehole. $Q^{i n}{ }_{t}, Q_{t}$ and $v$ is related by the equations 9 and 13 described in details in Brouyère et al. 2008.

Note that the dimensioning of a FVPDM experiment required an a priori estimation of a critical injection rate $Q_{c r}\left[\mathrm{~L}^{3} \mathrm{~T}^{-1}\right]$ (Equation 2). If the tracer injection flow rate $Q_{i n}$ exceeds $Q_{c r}$, it induces a hydraulic loading of the well, which completely cancels the transit flow rate, making the experiment invalid.

$Q_{c r}=\pi Q_{t}$

During the experiment, the tracer concentration first increases in the injection well, until reaching a plateau when steady state conditions are observed between the rate of tracer injection and the rate of tracer that is carried out of the well by the groundwater flow. The experiment can thus be divided into three phases (Figure 1). The first phase corresponds to transient concentrations and its duration is a function of the mixing volume $V_{w}$ and the transit 
flow rate $Q_{t}$. The steady state conditions are reached faster if the mixing volume is small and the transit flow rate is high. The second phase begins when the concentration $C_{w}$ in the well has stabilized, corresponding to steady state conditions. At this moment, $C_{w}$ only depends on the tracer injection flow rate and on the transit flow rate (see Brouyère et al. 2008 equation 16 for more details). As a consequence, the interpretation of a FVPDM test consists in (1) calculating the transit flow rate from the steady state $C_{w}$ and (2) in adjusting the mixing volume $\left(V_{w}\right)$ to fit the transient phase of the experiment. Allowing the system to reach this steady state strongly increases the precision of the FVPDM interpretation because the two unknown parameters of the FVPDM equation $\left(V_{w}\right.$ and $\left.Q_{t}\right)$ can be determined independently on different parts of the experimental curve. At the end of the experiment, the injection of tracer is stopped and this last phase corresponds to a classical dilution.

Considering Equation 1, the classical PDM (Equation 3) is only a specific case of the FVPDM, for $Q_{i n}=0$ and $C_{w, 0}>0 . C_{w}$ is related to the ratio of the transit flow rate on the mixing volume, in an exponential decay relation. This implies that the precision of the calculation of the transit flow rate $\left(Q_{t}\right)$ fully relies on an accurate external estimation of the mixing volume $\left(V_{w}\right)$. The transit flow rate could then be converted into a Darcy's flux $v\left[\mathrm{~L} \mathrm{~T}^{-1}\right]$ by the flow section $A\left[\mathrm{~L}^{2}\right]$ perpendicular to the undisturbed groundwater flow.

$C_{w}(t)=C_{w, 0} \times e^{-\frac{Q_{t}}{V_{w}}\left(t-t_{0}\right)}$

Considering the assumptions that are inherent to the classical PDM and FVPDM, both methods are affected by a priori limits. Classical PDM requires (1) steady state of the aquifer groundwater flow during a time sufficient for estimating $Q_{t},(2)$ an homogeneous mixing of a large amount of the tracer in the water column instantaneous at the beginning and continuously during the experiment and (3) the accurate and precise knowledge of the mixing 
volume. The quality of FVPDM relies on the duration of the experiment. In case of large mixing volume and/or limited groundwater flux, the FVPDM may require a long time to reach the steady state phase.

\subsection{Experimental test site}

The Stang Er Brune experimental test site is located at Ploemeur on the south coast of Brittany (France), in a crystalline rock aquifer constituted of micashists and granites (Figure 2a). This site belongs to the $\mathrm{H}+$ observatory (http://hplus.ore.fr/en/) which is a national network of highly instrumented research sites in subsurface hydrology. The site is equipped with three uncased, $0.12 \mathrm{~m}$ diameter wells of 80 to $100 \mathrm{~m}$ depth (B1, B2 and B3) and separated by less than $10 \mathrm{~m}$ and arranged in a triangular shape (Figure $2 \mathrm{~b}$ ). At this location the contact between the micashists and the underlying granite is observed at about $40 \mathrm{~m}$ below ground surface. The mean transmissivity obtained by various hydraulic tests in all the wells is around $10^{-3} \mathrm{~m}^{2} / \mathrm{s}$ (Le Borgne et al. 2006a and b). For the experiments described in this paper, two of the open boreholes (B1 and B2) were used. Wells B1 and B2 are intersected by 4 and 5 fracture zones, respectively, which are designated B1-1 to B1-4 and B2-1 to B2-5 (Figure 2b). This site offers several advantages. (1) The fractured aquifer has already been characterized by geophysical, thermal, hydraulic and tracer tests (Le Borgne et al. 2007, Dorn et al. 2012, Read et al. 2013). (2) Open boreholes without any casing are suitable for instrumentation with packers. (3) The small distances between the wells ensures a hydraulic connection that can be exploited for the purposes of the FVPDM experiments, i.e., to modify the transit flow rate $Q_{t}$ in a given fracture set in the test well by pumping one of the other wells. 


\subsection{Double packer experimental setup}

The experiments were performed in the deepest fracture zone identified in the well B1 (B1-4), where optical imagery showed two open fractures of $3 \mathrm{~cm}$ aperture in total at $78.7 \mathrm{~m}$ below the surface. The transmissivity of this fracture zone was estimated at $1.6 \times 10^{-4} \mathrm{~m}^{2} / \mathrm{s}$ (Klepikova et al., 2014). The flow section $A\left[\mathrm{~L}^{2}\right]$ perpendicular to the direction of the groundwater flow is then $0.0036 \mathrm{~m}^{2}$.

The experimental setup is designed to support FVPDM testing between a double packer system, which isolates the fracture zone (Figure 3). Vertical borehole flows are prevented and the dilution experiment is carried out within the delineated space. The length of the test chamber between the upper and lower inflatable packer was $1.2 \mathrm{~m}$. Pressure sensors were used to monitor piezometric head below, between and above the double packer in order to detect any leaky seals. A submersible pump was connected above the upper packer and linked to the test chamber to create a water circulation loop between the packers and the ground surface, where the loop was connected to a field fluorimeter, a pressure gauge, a water meter (to monitor flow rate of circulated water) and an electromagnetic pump for the low flow rate tracer injection. From the surface, the loop was completed at a connection allowing tracer injection at the bottom of the double packer test chamber (Figure 3).The B2 well, located $6 \mathrm{~m}$ away from B1, was equipped with a submersible pump to impose the groundwater fluxes around B2 and in all the surrounding fractures, including the fractured zone identified in B14. The FVPDM-PDM experiments were performed for different pumping rates in well B2 in order to investigate the ability and limitations of the two dilution methods to measure different groundwater fluxes. B2 pumping rates ranged from 0 and $2.4 \times 10^{-3} \mathrm{~m}^{3} / \mathrm{s}$ (0 to $144 \mathrm{~L} / \mathrm{min}$ ). Groundwater levels are also monitored in B2 and B3 wells using STS pressure sensors. 
FVPDM experiments were performed under specified pumping flow rates in well B2. When the conditions have stabilized in the vicinity of wells (no pressure variations greater than $1 \mathrm{~cm}$ in $5 \mathrm{~min}$ ), the tracer injection was started and the tracer concentration was monitored in the test chamber (thanks to the circulation loop). The circulation flow rate was precisely maintained at $4.2 \times 10^{-5} \mathrm{~m}^{3} / \mathrm{s}(2.52 \mathrm{~L} / \mathrm{min})$ and the tracer injection at $3.5 \times 10^{-7} \mathrm{~m}^{3} / \mathrm{s}(0.02 \mathrm{~L} / \mathrm{min})$ with a concentration of $207 \mathrm{ppb}$ of fluoresceine (CAS no. 518-47-8). In total, a succession of 10 FVPDM (F1 to F10) and 8 classical PDM (P1 to P8) experiments were performed iteratively (Table 1). Mixing volume $V_{w}$ and transit flow rate $Q_{t}$ were then adjusted on the experimental data for each test separately. For the PDM experiments, an external estimations of $V_{w}$ was used (i.e. independent of the interpretation of the exponential decay of tracer concentration observed during the PDM experiment). Uncertainties around adjusted values were estimated, and the results obtained for PDM and FVPDM compared and discussed.

\subsection{Uncertainties estimation using a Bayesian approach}

An adequate management of uncertainties is a critical issue in experimentation, and more generally in model calibration. Various sources of uncertainties co-exist (observations, experiment set up, simplified interpretation model) and might affect the parameter inference process. The Bayesian approach is a preferred method to perform inversion of nonlinear problems, and has been widely used to invert geophysical or hydrogeological data (e.g. Tarantola and Valette, 1982, Ghorbani et al., 2007, Fasbender et al. 2008). This approach consists in propagating the knowledge provided by measurements $m$ through a known and supposed to be exact forward model $G$ (here the dilution equations (1) and (3)), and to combine with an a-priori knowledge of model parameters (here, mixing volume $V_{w}$ and transit flow rate $Q_{t}$ ). Here, we will use a simplified definition of the posterior density function $p(\theta)$ 
for the parameter vector $\theta$ (Tarantola and Valette (1982). It can be calculated from the a-priori probability density function $\mu(\theta)$ (here taken as uniform), the sum of squared residuals (SSR) between the model with parameter $\theta$ and observations $\mathrm{m}$, as $S S R=\sum(m-G(\theta))^{2}$ and the standard deviation of measured data $\sigma$ as

$p(\theta)=\mu(\theta) \times e^{-\left(\frac{\sqrt{\operatorname{SSR}(\theta)}}{2 \sigma}\right)}$

Parameter uncertainties are finally computed as marginal probability density function.

\section{Results}

Figure 4 shows the experimental data of the succession of FVPDM-PDM tests conducted within the fracture B1-4 under different pumping rates in the nearby well B2. PDM experiments correspond to the periods when the tracer injection flow rate is null (Figure $4 \mathrm{~b}$ ). The cumulated measurement time exceeds 100 hours. As explained in previous sections, it is observed that the time to reach the steady state regime of FVPDM is longer when the pumping rate in $\mathrm{B} 2$, and thus the transit flow rates in fractures, decreases. The steady state concentration $C_{w}{ }^{s t a b}$ is also higher in this case, due to less important dilution effects.

Each phase of the experiment, corresponding to a specific pumping rate in the well $\mathrm{B} 2$ and to the PDM or FVPDM configuration, was interpreted separately. The adjustment of $V_{w}$ and $Q_{t}$ were performed by evaluating the RMS error between the experimental $C_{w}$ values and the $C_{w}$ values simulated using the analytical solutions of the PDM (Equation 2) and FVPDM (Equation 1). 


\subsection{Interpretation of a selected FVPDM and PDM experiment}

Figure 5 shows the results for the FVPDM and PDM experiments no. 3 (FVPDM 3 and PDM 3, see Table 1 for experimental setup parameters) for a specific pumping rate $\left(Q_{\text {pump }}\right)$ of $1.5 \times 10^{-3} \mathrm{~m}^{3} / \mathrm{s}(90 \mathrm{~L} / \mathrm{min})$ in well B2. Figure 5a shows the FVPDM experimental and simulated curves, which present the typical evolution of the tracer concentration with a transient phase at the beginning of the experiment and a steady state at the end of the test when the system has reached equilibrium. Figure $5 c$ is the RMS error plot between experimental data (FVPDM 3) and the simulated curves, obtained for different values of $V_{w}$ and $Q_{t}$. The graph shows that a minimum RMS value is relatively well identified, corresponding to a unique $\left(V_{w}, Q_{t}\right)$ pair that best fits the experimental data (Figure 5a). These values are $V_{w}$ equal to $35.6 \mathrm{~L}$ and $Q_{t}$ equal to $7.43 \times 10^{-6} \mathrm{~m}^{3} / \mathrm{s}$.

Figures $5 \mathrm{~b}$ and $5 \mathrm{~d}$ are similar but correspond to the PDM experiment no.3. The experimental curve (Figure 5b) shows the expected exponential decrease of the concentrations with time. However, with this method, it is rather difficult to adjust $V_{w}$ and $Q_{t}$ independently. A ratio $Q_{t} / V_{w}$ of $2.12 \times 10^{-4} \mathrm{~s}^{-1}$ can be fitted on experimental results and, theoretically, a large range of couples $\left(V_{w}, Q t\right)$ are possible. Accordingly, the RMS error obtained for the adjustment of $V_{w}$ and $Q_{t}$ (Figure 5d) shows that a minimum RMS value can not be identified and that the solution is not unique. Consequently, the mixing volume has to be precisely known to constrain the PDM model and to estimate the transit flow rate correctly.

Note that the values in the RMS plots depend on the data and duration of the experiments, but the shape of these plots will generally remain similar for longer experimental time. 


\subsection{External estimations of $\mathrm{Vw}$ for PDM interpretation}

Estimating the actual mixing volume based on the characteristics of the experimental setup is difficult, mainly because of the geometry of the well, the use of the double packer system, the presence of equipment in the test chamber, and the use of circulation loop. It has been estimated to approximately $29 \mathrm{~L}$, but the uncertainty on this value is unknown because the estimation was only based on the length and radius of the circulation pipes and on the dimension of the test chamber (radius of the well and distance between upper and lower packer when they are inflated) without taking into account the various equipment present within this delineated space. In this study, the actual mixing volume has been estimated using an alternative method based on an experimental artifact. At Figure 5, PDM and FVPDM curves show oscillations (sequential plateaus) at the beginning of the experiment that attenuate with time. This artifact is due to a non-instantaneous mixing of tracer in the whole recirculated water volume. At the beginning or stopping of the tracer injection, a front of high or low concentration develops when the tracer injection is started or stopped. The mean wavelength of these oscillations has been estimated using Fourier transformations for all the dilution experiments and is equal to $762 \mathrm{~s} \pm 119 \mathrm{~s}$ ( $95 \%$ confidence interval). It actually corresponds to the time necessary for the water to travel the entire water circulation loop. Considering a circulation flow rate $\left(Q_{r}\right)$ of $0.042 \mathrm{~L} / \mathrm{s}, V_{w}$ equals $32 \pm 5 \mathrm{~L}$.

Using this value, the transit flow $Q_{t}$ rate can be calculated from PDM experiments. For PDM no. 3 experiment, it is equal to $6.82 \times 10^{-6} \mathrm{~m}^{3} / \mathrm{s}$. Both values for $V_{w}(32 \mathrm{~L})$ and $Q_{t}\left(6.82 \times 10^{-}\right.$ $\left.{ }^{6} \mathrm{~m}^{3} / \mathrm{s}\right)$ agree with FVPDM estimates $\left(V_{w}=35.6 \mathrm{~L}\right.$ and $\left.Q_{t}=7.43 \times 10^{-6} \mathrm{~m}^{3} / \mathrm{s}\right)$ within $10 \%$ of error. 


\subsection{Evaluation of uncertainties on the adjustment of $V_{w}$ and $Q_{t}$ for a selected FVPDM and PDM test}

Both FVPDM and PDM can be used to estimate groundwater fluxes within the B1-4 fracture zone. However, the two methods are different and the confidence to be attributed to the results has to be determined. The uncertainties on calculated fluxes are related to the adjustment of the analytical solutions on experimental data and to the confidence on the $V_{w}$ value, in the case of the PDM. The analysis of uncertainties is based on the exploration of $Q_{t}$ and $V_{w}$ values between specified intervals, using Equations 1 and 2. The RMS errors between the experimental and simulated $C_{w}$ values have been converted into probabilities according to equation 4 (see Section 2.4).

The probabilities are calculated for the FVPDM and PDM experiments no.3. They are multiplied with the normal distribution related to the estimation of $V_{w}$, equal to $32 \mathrm{~L} \pm 5 \mathrm{~L}$, to draw the probability plots presented in Figure 6. These plots are further used to calculate the most probable value for $V_{w}$ and $Q_{t}$ and the $95 \%$ confidence intervals (Table 2), for both PDM and FVPDM. Considering the results related to the experiments no.3, the $95 \%$ confidence interval on the calculated transit flow rate is more than five times smaller for the FVPDM than for the PDM. These methodology and results are also dependent on the respective durations of the experiments, which are not equivalent in this case. To conclude about the general performances of both methods, the issues related to the duration of the different experiments are further discussed in the next section.

\subsection{Influence of the duration of the experiment}

The accuracy of the adjusted values for the PDM and FVPDM increases with the duration of the experiment. Concerning the FVPDM, this accuracy reaches a maximum value when the 
tracer concentration has stabilized in the injection well. The time to reach this steady state increases as the mixing volume increases and the transit flow rate decreases. To compare the FVPDM and PDM including the 'time' issue, uncertainties on the adjusted $Q_{t}$ are investigated as a function of a normalized experiment duration. A normalized time $t^{*}$ independent of $V_{w}$ and $Q_{t}$ is used and is obtained by dividing the mixing volume $V_{w}$ by the critical injection flow rate $Q_{c r}$ (see section 2.1).

$$
t^{*}=\frac{V_{w}}{Q_{c r}}=\frac{V_{w}}{\pi \times Q_{t}}
$$

The uncertainty around $Q_{t}{ }^{0}$ has been calculated for the FVPDM and PDM experiments no.3, but by artificially considering on specific fractions of the available experimental data, corresponding to specific numbers of $t^{*}$ (Figure 7). Considering Equation 1, the critical time $\mathrm{t}_{\mathrm{c}}$, necessary to reach $99 \%$ of the steady state concentration, is reached after $13.9 t^{*}$. If $Q_{i n}$ is small enough and neglected in comparison to $Q_{t}$, this critical time tends to $14.5 t^{*}$. This is in accordance with the results shown in Figure 7. The total duration of the FVPDM no.3 is 16.8 $t^{*}$. The corresponding non dimensional time for the PDM no.3 allowed only a duration of $4.5 t^{*}$

The uncertainty (P05-P95) around the calculated transit flow rate $Q_{t}$ decreases significantly with time for the FVDPM. The FVPDM is less precise for the determination of $Q_{t}$ for short experiment durations (t lower that approximately $4 t^{*}$ or $0.29 t_{c}$ ) and clearly overestimates the value of $Q_{t}$. In this field campaign, this is partly explained by the non-uniform mixing of tracer in the circulated volume, which disturbed the increase of tracer concentration at the beginning of the experiment. It also comes from the time required for a good estimate. But for long experiment, the accuracy of measurements becomes very good, with an uncertainty less than $10 \%$ of $Q_{t}$, for duration higher than $10 t *$ or $0.72 t_{c}$. Concerning the classical PDM, the 
uncertainty also decreases with time due to the attenuation of oscillations in tracer concentration at the beginning of the dilution and but seems to stay relatively high, around $25 \%$ of $Q_{t}$. But this uncertainty is only dependent on the precision of the externally estimated $V_{w}$ (see previous sections). Although the uncertainty is relatively high, the mean estimates are acceptable for all times including short times.

Whatever the duration of the PDM test, a complete FVPDM (i.e. a FVPDM that reaches the steady state) is more precise. The 'threshold time', when the FVPDM becomes more precise than the PDM is in this case equal to $0.29 t_{c}$, but it depends on the precision of the externally estimated $V_{w}$ used in the PDM experiments, and increases as $V_{w}$ is more accurately estimated.

\subsection{Comparison of results for different fracture flow rates}

All the dilution experiments have been interpreted separately, considering an a priori estimated mixing volume of $32 \pm 5$ liters and an unknown transit flow rate. Results are presented in Table 3 and in Figure 8 . The critical time $t_{c}$ corresponds to the time necessary to reach $99 \%$ of the FVPDM steady state tracer concentration. It is estimated from Equation 1 considering that the initial tracer concentration is zero. This critical time can be compared to the actual duration of each experiment to estimate if steady state has been reached.

The relationship between the transit flow rate in the fracture B1-4 determined by both FVPDM and PDM and the pumping rate applied in B2 (Figure 8) appears to be linear. A slight deviation may be observed for the highest pumping rates, but this is difficult to confirm, given the calculated uncertainties (see discussion below). However, the relationship between the drawdown and the pumping rate in B2 (data Table 3) also presents a slight deviation from the linear behavior, suggesting that flow in the system may not be fully Darcyan. 
The adjusted transit flow rates for all the dilution experiments are always higher for the FVPDM (hollow circles) than for the PDM (grey squares), but the confidence intervals are intersecting. Concerning the PDM, the information on the mixing volume is only provided externally (in this case, thanks to the oscillations artifacts), and it impacts the estimation of the transit flow rate. The bias between FVPDM and PDM results (Figure 8 and Table 3) can be explained by underestimation of this mixing volume. This volume was estimated to $29 \mathrm{~L}$ based on geometric characteristics, to $32 \pm 5 \mathrm{~L}$ based the oscillations in the experimental curves (Section 3.2), and a bit higher for the most accurate FVPDM experiments (FVPDM 3 and FVPDM 9 in Table 3). If the PDM is interpreted using a higher value for $V_{w}$, as suggested by the most accurate FVPDM tests, the adjusted $Q_{t}$ converge for the FVPDM and PDM tests. This is indeed logical since the PDM is only the last part of a full FVPDM experiment. This also illustrates the need for precise external estimation of $V_{w}$, if using PDM experiments only. This level of precision is however not always possible.

The FVPDM generally presents a better precision with smaller confidence intervals, which increase with the calculated transit flow rate and pumping flow rate in well B2 (Figure 8). The differences are due to a higher sensitivity of the FVPDM to the experimental data, and because the FVPDM is also able to provide an independent information on both transit flow rate and mixing volume. In this case, the results of Table 3 show that the adjusted $V_{w}$ varies for the different FVPDM experiments. These variations of adjusted $V_{w}$ can be due to the oscillations of tracer concentrations that disturb the rising part of the FVPDM curve and observation errors. This is precisely the part of the curve which is used to adjust the value of the mixing volume. This is particularly the case when the duration of the FVPDM experiment that has not last enough to reach the steady state and therefore limit the precision of the adjustments of $V_{w}$ and $Q_{t}$, as explained in previous sections. 
The transit flow rate estimated for the FVPDM no. 2 carried out with a pumping rate of $1.86 \times 10^{-3} \mathrm{~m}^{3} / \mathrm{s}$ at well $\mathrm{B} 2$ presents a more important uncertainty and appears to deviate, compared to the other FVPDM experiments. This can be explained by a short experiment duration (see Section 3.4 and Table 3) of only $0.64 t_{c}$, leading to more uncertainty and potential errors. Note that the results of FVPDM no. 1 are also affected by some 'noise' in the experimental data (see Figure 4), due to a technical problem, leading to more uncertainty.

No transit flow rate could be calculated for the FVPDM no.5 and no.8 performed with no pumping at the well B2 (i.e. under natural ambient groundwater flow in the aquifer). Under these slow groundwater flow conditions, the critical flow rate determined by the PDM no. 4 and 6 is around $2 \times 10^{-7} \mathrm{~m}^{3} / \mathrm{s}$. The injection of tracer at a rate of $3.5 \times 10^{-7} \mathrm{~m}^{3} / \mathrm{s}$ (the lowest that can be achieved with the available equipment) exceeds thus the critical injection rate $Q_{c r}$ making the experiment invalid as explained in Section 2.1. With the available tracer injection pump and an injection flow rate $Q_{i n}$ of $6 \times 10^{-8} \mathrm{~m}^{3} / \mathrm{s}, t_{c}$ would have been around 10 days. 


\section{Discussion}

A comparison of the present results with the experiments of Novakovski (2006) that performed PDM between packer shows that the FVPDM experimental setup used during this field campaign can investigate a range of Darcy's fluxes transit flow rate higher than Novakowski's PDM. Nevertheless the FVPDM offers a distinct estimation of $V_{w}$ that is unavailable with the PDM. The measurement of fracture flow velocities of Novakowski ranges from $1.2 \times 10^{-5}$ to $4.5 \times 10^{-3} \mathrm{~m} / \mathrm{s}$, the present FVPDM performed at Ploemeur measured fractures flow from $3.1 \times 10^{-3}$ to $3.8 \times 10^{-2} \mathrm{~m} / \mathrm{s}$.

Considering these experimental data for dilution experiment no.3, the FVPDM becomes more precise than the PDM from a time corresponding to approximately $4 t^{*}$ or $0.29 t_{c}$. This result is consistent with the initial recommendation of Brouyère et al (2008) that recommended an experiment duration of 5 to 7 times $t^{*}$ to ensure reaching the steady state of the FVPDM. The same calculation has been carried out for all the dilution tests and shows identical trends with the precision on the adjusted $\mathrm{Q}_{\mathrm{t}}$ increasing with time for FVPDM. This precision remains high for PDM, whatever the duration of the experiment, but mainly depends on the accuracy of the external estimation of $V_{w}$. As a conclusion, classical PDM seems to be a technique suitable for rapid results, including a large range of groundwater fluxes. However, this study has highlighted the crucial need for accuracy regarding the a priori knowledge of $V_{w}$ when accuracy using PDM experiments. This accuracy actually directly affects the performance and possible bias of PDM results. At the contrary, the FVPDM is more precise, even without estimation of $V_{w}$, but may require long experiment durations under specific conditions. In case of very slow groundwater flow and large mixing volume, the time required to reach steady state may actually become very long and unmanageable. For example, if the transit flow rate $Q_{t}$ is lower than $10^{-7} \mathrm{~m}^{3} / \mathrm{s}$ and the mixing volume is higher than $10 \mathrm{~L}$ simultaneously, the time 
to reach the critical time $t_{c}$ (or $5 t^{*}$ ) exceeds 48 hours. Furthermore, the estimation of the mixing volume $V_{w}$ by the FVPDM is more robust than simply by using the geometry of the well. Vw determined by FVPDM is an apparent value that takes into account all the water that participates to the mixing of tracer. For example it can integrate an unknown dead-end fracture that would not be considered with a classic PDM and bias the result of the transit flow rate.

Considering the results of Table 3, the ratio between the transit flow rate calculated with FVPDM and the pumping flow rate in B2, ranges between 170 and 230, approximately. If the fluxes are assumed uniformly distributed around B2, this ratio should be equal to 754 . This last value is obtained by considering the following values. The distance between B1 and B2 is equal to $6 \mathrm{~m}$. Calculated flow rates correspond to a $0.1 \mathrm{~m}$ section (the diameter of $\mathrm{B} 1$ ) of the circle intercepting B1, and having B2 as a center. Finally, only 50\% the total pumping flow rate in B2 is coming from the B1-4 fracture. This was evidenced by Read et al. (2013) using heat tracer tests. The lower experimental ratio, compared to the theoretical ratio, highlights the fact that fluxes are more probably non-uniform within the fractures, for example with some possible channelization.

From a practical point of view, an improvement of the experimental setup could be to get rid of the circulation loop by placing all the surface equipment (tracer injection pump, fluorimeter and mixing propeller) into the test chamber. In this case, the water present in the loop represents $25 \%$ of the total mixing volume. Such a reduction of $V_{w}$ would significantly decrease the time to reach a steady state for the FVPDM and avoid the oscillatory effect of the circulation of tracer along the loop. The use of a dosing pump with smaller minimum tracer injection rate would also allowed for determination of smaller transit flow rate such as in natural flow conditions. Moreover, an inflatable double packer of this size (more than 4 
meters) is not easy to use in the field and requires heavy equipment to be installed in the well. The development of a specific probe gathering all the required equipment into a compact size device will also improve the practicality of the method.

The FVPDM no. 4 and 5; 6, 7 and 8; and 9 and 10 were performed consecutively by maintaining the injection of tracer and changing the pumping rate at the nearby well. The changes in the groundwater flow velocity were recorded by those continuous FVPDM experiments. This highlights that the FVPDM is capable of monitoring temporal changes of groundwater flow. On the contrary, a variable groundwater flux precludes the interpretation of classical PDM because this method is based on the hypothesis that the groundwater flux is constant. Development of the FVPDM for long term monitoring of transient groundwater flow constitutes the most interesting perspective. For that, the experimental setup has to be optimized by reducing the tracer injection flow rate to avoid frequent refill of the tracer solution tank. And finally a mathematical model has to be developed to interpret the FVPDM experiment in case of transient groundwater flow. 


\section{Conclusions}

The Finite Volume Point Dilution Method has been applied to measure groundwater fluxes within a local fracture zone of the crystalline aquifer of Ploemeur, France. This manipulation is the first successful application of the FVPDM technique in a fractured aquifer and using a double packer system. Experiments have been carried out for variable groundwater flow, induced by pumping in a well located close to the tested well. In total, 10 FVPDM and 8 classical PDM were performed to compare the two methods.

Measurements of groundwater fluxes by classical PDM provide good estimates, even for short times experiments, if $V_{w}$ can be precisely estimated. With this method, the precision on the calculated groundwater flux fully depends on the precision of the estimation of the water circulation volume. On the contrary, the FVPDM allows for an independent estimation of both groundwater flow rate $Q t$ and water mixing volume $V_{w}$. The best precision is obtained when steady state conditions are reached for tracer concentration in the tested well, which may require long experimental durations. Classical PDM seems to be more accurate than FVPDM for short experiments provided the mixing volume is accurately known. FVPDM generally provides a better accuracy but requires longer experiment durations. The 'threshold' after which FVPDM becomes more accurate than PDM depends on the precision reached in the external estimation of the mixing volume.

The present experiments also highlight the ability of the FVPDM to continuously monitor continuous transient groundwater fluxes. Two short term perspectives could be (1) to develop a mathematical model to interpret a fully transient FVPDM test and (2) to follow a multiple stages pumping test performed at a well with FVPDM monitoring at some nearby piezometer 
to investigate the benefits of groundwater fluxes information in the interpretation of pumping tests.

In conclusion, both methods are complementary and can investigate the same range of groundwater fluxes. The classical PDM should be used for rapid estimation of steady state groundwater flux. The FVPDM is a more precise method but requires longer duration experiment to achieve a good precision if the investigated groundwater fluxes are low and/or if the mixing volume is large, and has a strong development potential for monitoring of transient groundwater fluxes. 


\section{Acknowledgements}

This work has been supported by research grants from the University of Liège and FNRS

Belgium no. 1.5060 .12 , by the CLIMAWAT project (Adapting to the Impacts of Climate Change on Groundwater Quantity and Quality - EU-RDF INTERREG IVA (Channel)

France-England program), and by the national network of hydrogeological sites $\mathrm{H}+$ and the ANR project CRITEX ANR-11-EQPX-0011. 


\section{REFERENCES}

Brainerd, R. J., and Robbins, G. A. (2004). A tracer dilution method for fracture characterization in bedrock wells. Ground Water, 42(5), 774-780.

Bright, J., Wang, F. and Close, M. (2002). Influence of the amount of available K data on uncertainty about contaminant transport prediction. Ground Water, 40 (5), 529-534.

Brouyère, S. (2003). Modeling tracer injection and well-aquifer interactions: A new mathematical and numerical approach. Water Resources Research, 39(3), 1070-1075.

Brouyère, S., (2001). Study and modelling of transport and retardation of solutes in variably saturated media. PhD Thesis, Faculté des Sciences Apliquées, Laboratoire de géologie de l’ingénieur, d’Hydrogéologie et de Prospection géophysique, Université de Liège, Liège, Belgium, 307 p.

Brouyère, S., Batlle-Aguilar, J., Goderniaux, P., and Dassargues, A. (2008). A New Tracer Technique for Monitoring Groundwater Fluxes: The Finite Volume Point Dilution Method. Journal of Contaminant Hydrology, 95(3-4), 121-40.

Brouyère, S., Carabin, G., and Dassargues, A. (2005). Influence of injection conditions on field tracer experiments. Ground Water, 43(3), 389-400.

Devlin, J.F. and McElwee, C.D. (2007). Effects of measurement error on horizontal hydraulic gradient estimates. Ground Water, 45 (1), 62-73.

Dorn, C., Linde, N., Le Borgne, T., Bour, O., \& Klepikova, M. (2012). Inferring transport characteristics in a fractured rock aquifer by combining single-hole ground-penetrating radar reflection monitoring and tracer test data. Water Resources Research, 48(11), W11521. http://doi.wiley.com/10.1029/2011WR011739 
Drost, W., Klotz, D., Koch, A., Moser, H., Neumaier, F., and Rauert, W. (1968). Point dilution methods of investigating ground water flow by means of radioisotopes. Water Resources Research, 4(1), 125-146.

Englert, A., Le Borgne, T., Bour, O., Klepikova, M., and Lavenant, N. (2011). Local Fracture Flow Measurement by The Double Packer Dilution Test. NOVCARE 2011, 19p.

Fasbender, D., Peeters, L., Bogaert, P. and Dassargues, A. (2008). Bayesian data fusion applied to water table spatial mapping. Water Resources Research 44(12), W12422. http://dx.doi.org/10.1029/2008WR006921

Ghorbani, A., Camerlynck, C., Florsch, N., Cosenza, P. and Revil, A. (2007). Bayesian inference of the Cole-Cole parameters from time- and frequency-domain induced polarization. Geophysical Prospecting, 55, 589-605. doi: 10.1111/j.1365-2478.2007.00627.x

Goderniaux, P., S. Brouyere, A. Gutierrez, and N. Baran (2010), Multi-tracer tests to evaluate the hydraulic setting of a complex aquifer system (Brévilles spring catchment, France). Hydrogeology Journal, 18(7), 1729-1740.

Hall, S. H. (1996). Practical single-well tracer methods for aquifer testing. In Workshop netbook, Tenth national outdoor action conference and exposition, $11 \mathrm{p}$.

Hatfield, K., Annable, M. D., Cho, J., Rao, P. S. C., and Klammler, H. (2004). A direct passive method for measuring water and contaminant fluxes in porous media. Journal of Contaminant Hydrology, 75(3-4), 155-181.

Havely, E., Moser, H., Zellhofer, O., and Zuber, A. (1967). Borehole dilution techniques a critical review. In Isotope in Hydrology, I.A.E.A., Vienna, 531-564.

Huang, J. and Goltz, M.N. (2005). A three-dimensional analytical model to simulate groundwater flow during operation of recirculating wells. Journal of Hydrology, 314, 67-77. 
Kading, H.W. (1976). Horizontal spinner, a new production logging technique. The Log Analyst XVII (5), 3-7.

Kaufman, W.J. and Todd, D.K. (1962). Application of tritium tracer to canal seepage measurements. International Atomic Energy Agency, Tritium in the Physical and Biological Sciences 1, 83-94.

Kearl, P.M. (1997). Observations of particle movement in a monitoring well using the colloidal borescope. Journal of Hydrology 200 (1-4), 323-344.

Klepikova, M. V., T. Le Borgne, O. Bour, K. Gallagher, R. Hochreutener and N. Lavenant, Passive temperature tomography experiments in fractured media, Journal of Hydrology 512 (2014) 549562, doi: 10.1016/j.jhydrol.2014.03.018

Klotz, D., Moser, H., and Trimborn, P. (1979). Single borehole techniques present status and examples of recent applications. In Isotope in Hydrology, I.A.E.A., Neuherberg, 150-179.

Le Borgne, T., Bour, O., Paillet, F., and Caudal, J. P. (2006a). Assessment of preferential flow path connectivity and hydraulic properties at single-borehole and cross-borehole scales in a fractured aquifer. Journal of Hydrology, 328(1-2), 347-359. doi:10.1016/j.jhydrol.2005.12.029

Le Borgne, T., Paillet, F., Bour, O., and Caudal, J.-P. (2006b). Cross-borehole flowmeter tests for transient heads in heterogeneous aquifers. Ground water, 44(3), 444-452. doi:10.1111/j.1745$6584.2005 .00150 . \mathrm{x}$

Le Borgne, T., Bour, O., Riley, M. S., Gouze, P., Pezard, P. a., Belghoul, A., Lods, G., et al. (2007). Comparison of alternative methodologies for identifying and characterizing preferential flow paths in heterogeneous aquifers. Journal of Hydrology, 345(3-4), 134-148. doi:10.1016/j.jhydrol.2007.07.007

Momii, K., K. Jinno, and F. Hirano. 1993. Laboratory studies on a new laser Doppler velocimeter system for horizontal ground water velocity measurement in a borehole. Water Resources Research 29 (2), 283-292. 
Novakowski, K. S., Bickerton, G., and Lapcevic, P. (2004). Interpretation of injection-withdrawal tracer experiments conducted between two wells in a large single fracture. Journal of Contaminant Hydrology, 73(1-4), 227-247. doi:10.1016/j.jconhyd.2004.02.001

Novakowski, K. S., Bickerton, G., Lapcevic, P., Voralek, J., and Ross, N. (2006). Measurements of groundwater velocity in discrete rock fractures. Journal of contaminant hydrology, 82(1-2), 4460. doi:10.1016/j.jconhyd.2005.09.001

Novakowski, K. S., Lapcevic, P., Voralek, J., and Bickerton, G. (1995). Preliminary interpretation of tracer experiments conducted in a discrete rock fracture under conditions of natural flow. Geophysical Research Letters, 22(11), 1417-1420.

Pitrak, M., Mares, S., and Kobr, M. (2007). A simple borehole dilution technique in measuring horizontal ground water flow. Ground Water, 45(1), 89-92.

Raven, K., and Novakowski, K. S. (1988). Interpretation of field tracer tests of a single fracture using a transient solute storage model. Water Resources Research, 24(12), 2019-2032.

Read, T., Bour, O., Bense, V., Le Borgne, T., Goderniaux, P., Klepikova, M. V., Hochreutener, R., Lavenant, N. and Boschero, V. (2013). Characterizing groundwater flow and heat transport in fractured rock using fiber-optic distributed temperature sensing. Geophysical Research Letters, 40(10), 2055-2059.

Ruelleu, S., Moreau, F., Bour, O., Gapais, D., and Martelet, G. (2010). Impact of gently dipping discontinuities on basement aquifer recharge: An example from Ploemeur (Brittany, France). Journal of Applied Geophysics, 70(2), 161-168. doi:10.1016/j.jappgeo.2009.12.007

Sale, T., Taylor, G. R., Iltis, G., and Lyverse, M. (2007). Measurement of LNAPL flow using singlewell tracer dilution techniques. Ground Water, 45(5), 569-578. doi:10.1111/j.17456584.2007.00337.x 
Sanford, W. E., Cook, P. G., Robinson, N. I., and Weatherill, D. (2006). Tracer mass recovery in fractured aquifers estimated from multiple well tests. Ground water, 44(4), 564-573. doi:10.1111/j.1745-6584.2006.00161.x

Tarantola A. and Valette B. (1982). Inverse problems = quest for information. Journal of Geophysics, $50,159-170$.

West, A. C. F., Novakowski, K. S., and Gazor, S. (2006). A maximum likelihood estimator for bedrock fracture transmissivities and its application to the analysis and design of borehole hydraulic tests. Water Resources Research, 42(6), 1-12. doi:10.1029/2004WR003685

West, L. J., and Odling, N. E. (2007). Characterization of a multilayer aquifer using open well dilution tests. Ground Water, 45(1), 74-84. doi:10.1111/j.1745-6584.2006.00262.x

Witherspoon, P., Wang, J., Iwai, K., and Gale, J. (1980). Validity of cubic law for fluid flow in a deformable rock fracture. Water Resources Research, 16(6), 1016-1024.

Zha, Y., Yeh, T.-C. J., Mao, D., Yang, J. and Lu, W. (2014). Usefulness of flux measurements during hydraulic tomographic survey for mapping hydraulic conductivity distribution in a fractured medium. Advances in Water Resources, 71, 162-176.

Zlotnik, V.A. and McGuire, V.L. (1998). Multi-level slug tests in highly permeable formations: 1. Modification of the Springer-Gelhar (SG) model. Journal of Hydrology, 204 (1-4), 271-282

Zlotnik, V.A. and Zurbuchen, B.R. (2003). Field study of hydraulic conductivity in a heterogeneous aquifer: Comparison of single-borehole measurements using different instruments, Water Resources Research, 39 (4), WR001415, 12p. 


\section{FIGURE CAPTIONS}

Figure 1: Evolution of tracer concentrations $(C w)$ in a well where a FVPDM is performed. The steady state regime is reached when the mass flux of tracer injected in the well equilibrate with the mass flux of tracer flushed out of the well by the groundwater flow that transit by the well screen. The experiment ends as a classical PDM when the injection of tracer is stopped.

Figure 2: a) Location of the Ploemeur test site. b) Configuration of the three 90 meters deep wells (B1, B2, B3), and the fracture network. Dashed lines represents the hydraulic connections by group of fractures between B1 and B2 identified by tracer tests (Le Borgne et al. 2007, Dorn et al. 2012).

Figure 3: Experimental setup limiting vertically the investigated fracture zone with double packers. The dilution tests are performed within this $1.2 \mathrm{~m}$ delineated test chamber. The corresponding volume of groundwater is mixed using a pump and circulated to the surface, where tracer is injected using a dosing pump. Concentration of tracer in the loop is monitored using a field fluorimeter placed in line. An immersed pump placed in the nearby well B2 allows the modification of the groundwater fluxes in the fracture B1-4. The aperture of the fractures are not at scale.

Figure 4: Evolution of tracer concentration (c) during the measurement of groundwater flow by FVPDM and PDM in the B1-4 fracture. The distinction between natural and forced hydraulic conditions is represented by the pumping rate applied in the well B2 (a). The distinction between FVPDM and PDM experiments is figured by the tracer injection flow rate (b), PDM being performed when $Q_{i n}$ is null. Discontinuity in the measurement of tracer concentration is due to stops of the fluorimeter during equipment manipulations. Spike of tracer concentration during FVPDM no.1 is due to a technical problem but does not prevent the interpretation of the test. The id of the FVPDM and PDM successive experiment are named in figure $4 \mathrm{~d}$.

Figure 5: Experimental data (grey points) and adjusted analytical solutions (black crosses) of FVPDM no.3 (a) and PDM no.3 (b) experiments corresponding to a pumping rate of $1.5 \times 10^{-3} \mathrm{~m}^{3} / \mathrm{s}(90 \mathrm{~L} / \mathrm{min})$ in the B2 well. (c) and (d) are the RMS error plot for the FVPDM and PDM experiments for the 
adjustment of the mixing volume and the groundwater transit flow rate. A unique pair of $Q_{t} / V_{w}$ value fits the FVPDM equation $\left(V_{w}=35.6 \mathrm{~L}, Q_{t}=7.43 \times 10^{-6} \mathrm{~m}^{3} / \mathrm{s}\right)$. On the contrary, a wide range of $Q_{t} / V_{w}$ pairs that satisfies the PDM equation without being able to determine a most probable one $\left(Q_{N} / V_{w}=2.12 \times 10^{-4} \mathrm{~s}^{-1}\right)$. Note the oscillations of tracer concentration in the well (sequential plateaus) at the beginning of FVPDM and PDM experiment.

Figure 6: Adjustment of $V_{w}$ and $Q_{t}$ for the experiments $\mathrm{n}^{\circ} 3$ (with pumping at $1.5 \times 10^{-3} \mathrm{~m}^{3} / \mathrm{h}$ in B2) considering an a priori known $V_{w}$ of $32 \pm 5 \mathrm{~L}$.

Figure 7: Evolution of the calculated $Q_{t}$ and the $95 \%$ confidence intervals, as a function of the duration of the experiment for FVPDM no.3 (hollow circles) and PDM no.3 (grey squares) (pumping rate of $1.5 \times 10^{-3} \mathrm{~m}^{3} / \mathrm{s}$ in $\mathrm{B} 2$ ). $t^{*}$ corresponds to a normalized time allowing the comparison between dilution experiments with different transit flow rates.

Figure 8: A linear relation is observed between the pumping rate applied in the well B2 and the groundwater flow rate observed in the fracture B1-4. The transit flow rate $\left(Q_{t}\right)$ adjusted for all the dilution experiments are always higher for the FVPDM (hollow circles) than for the PDM (grey squares) due to difference of adjusted $V_{w}$ and $95 \%$ confidence intervals are always shorter for FVPDM than PDM. 


\section{TABLE CAPTIONS}

Table 1: Characteristics and sequence of tracer injections for FVPDM and PDM experiments on well B1-4. $C_{w, O}$ is the initial tracer concentration in well B1-4 at the beginning of the experiment. $Q_{p u m p}$ corresponds to the pumping rate at well $\mathrm{B} 2$ and $Q_{i n j}$ to the tracer injection flow rate at a concentration $C_{i n}$ of $207 \mathrm{ppb}$.

Table 2: Results of the adjustment of the parameters $Q_{t}$ and $V_{w}$ considering a probability density function on $V_{w}$ of $32 \pm 5 \mathrm{~L}$ for PDM and FVPDM experiment no.3.

Table 3: Result of the dilution experiments carried out on B1-4. Uncertainties on $V_{w}$ and $Q_{t}$ correspond to the calculated confidence interval at $95 \% . t_{c}$ is the critical time necessary to reach $99 \%$ of the steady state concentration (* not interpretable). 


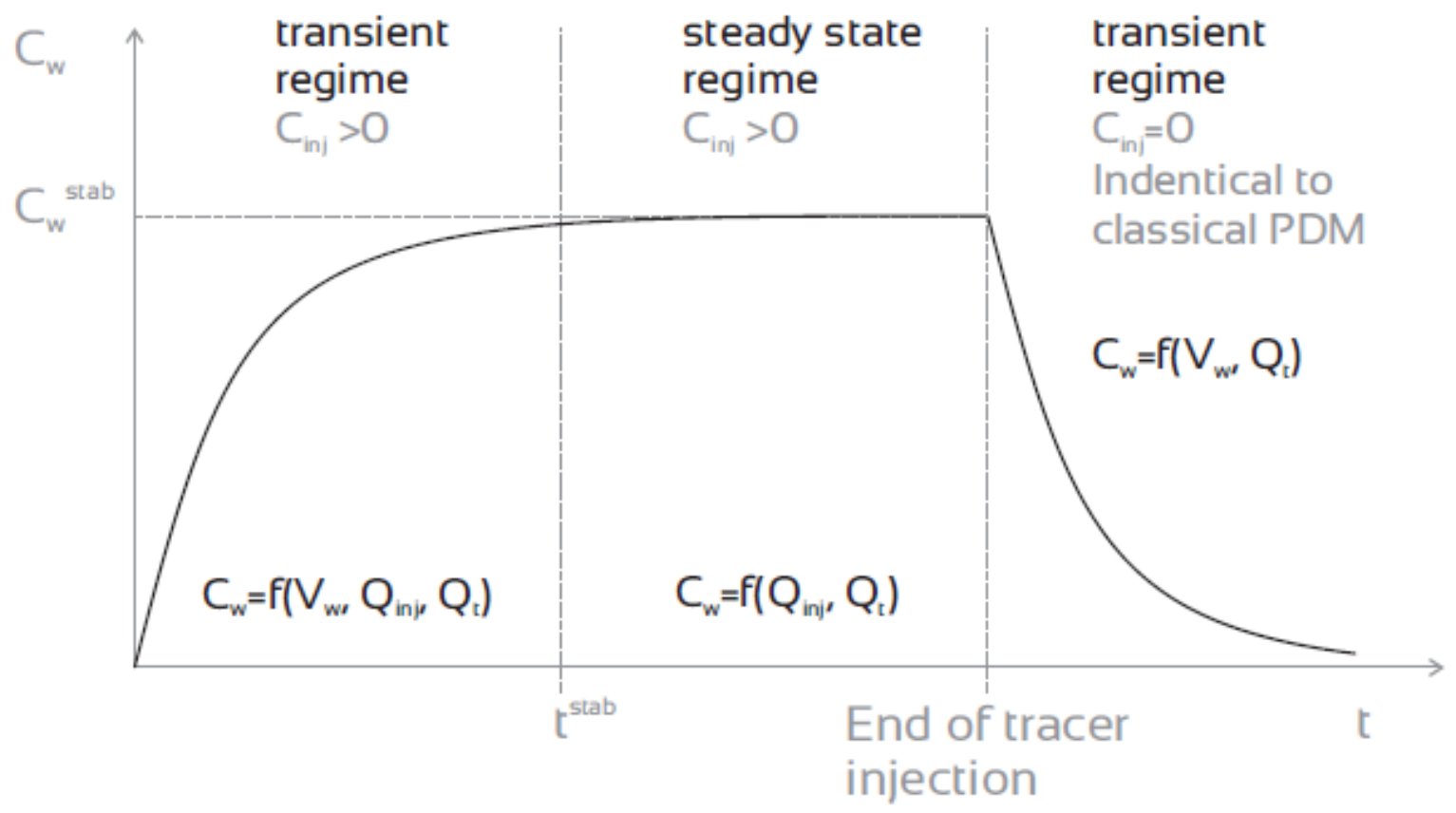

Figure 1 
Figure2
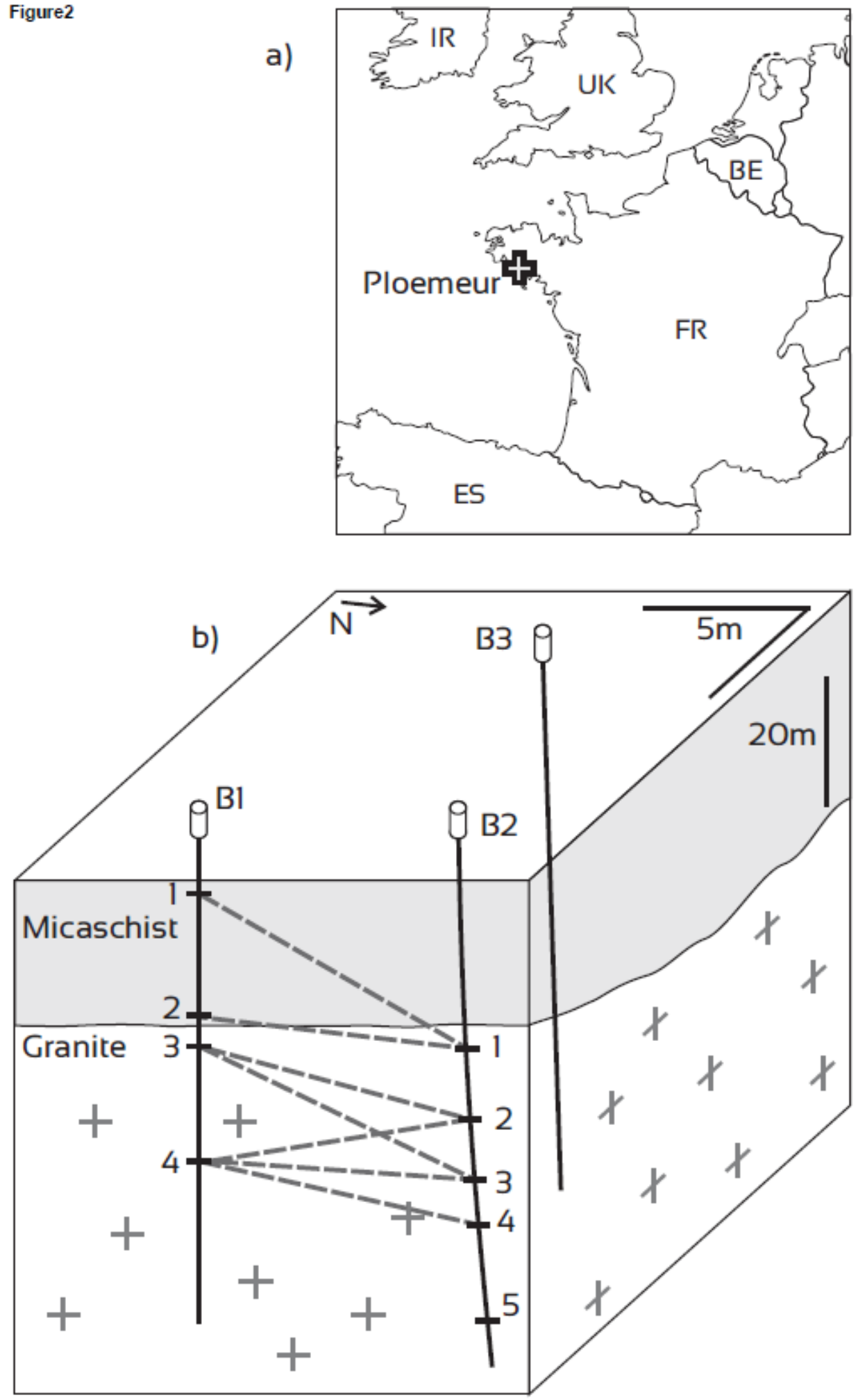

Figure 2 
Figure3

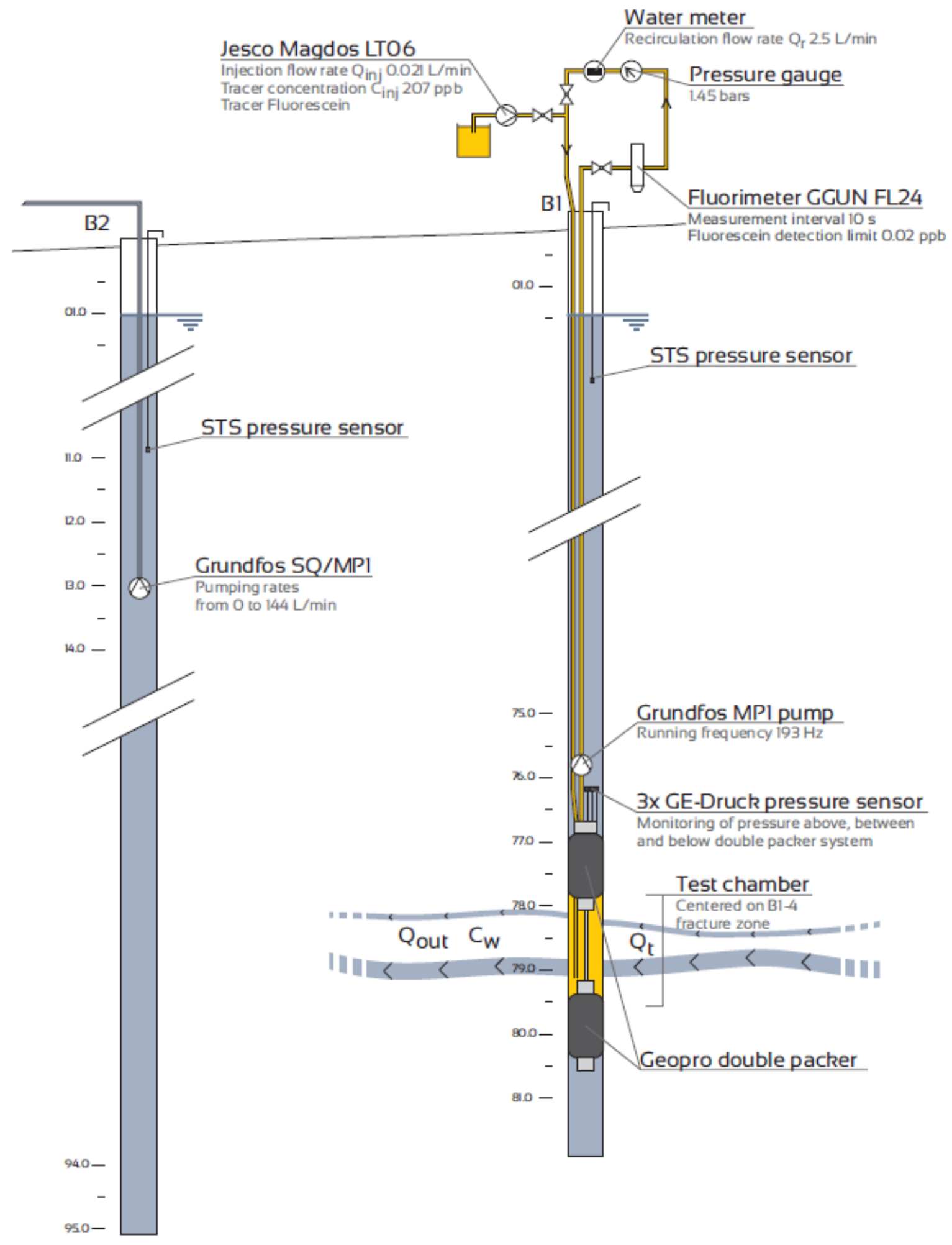

Figure 3 


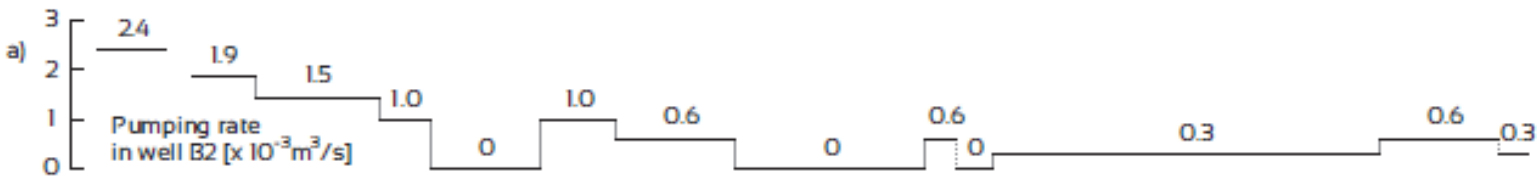

Tracer injection

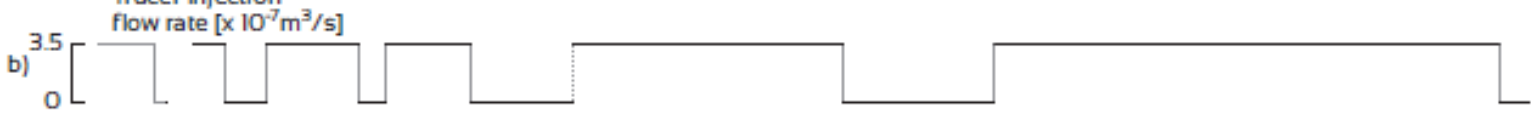

c) ${ }^{70}[0-$ Uranine concentration [ppb]

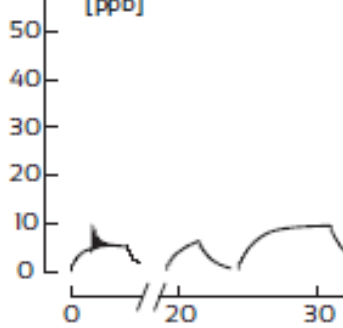

d)

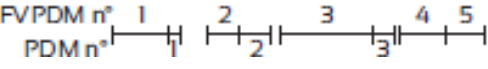
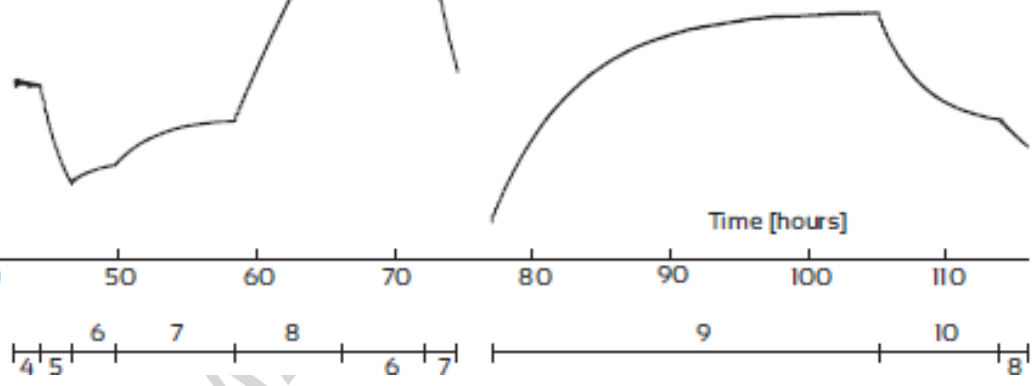

Time [hours]

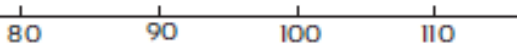

Figure 4 
a)
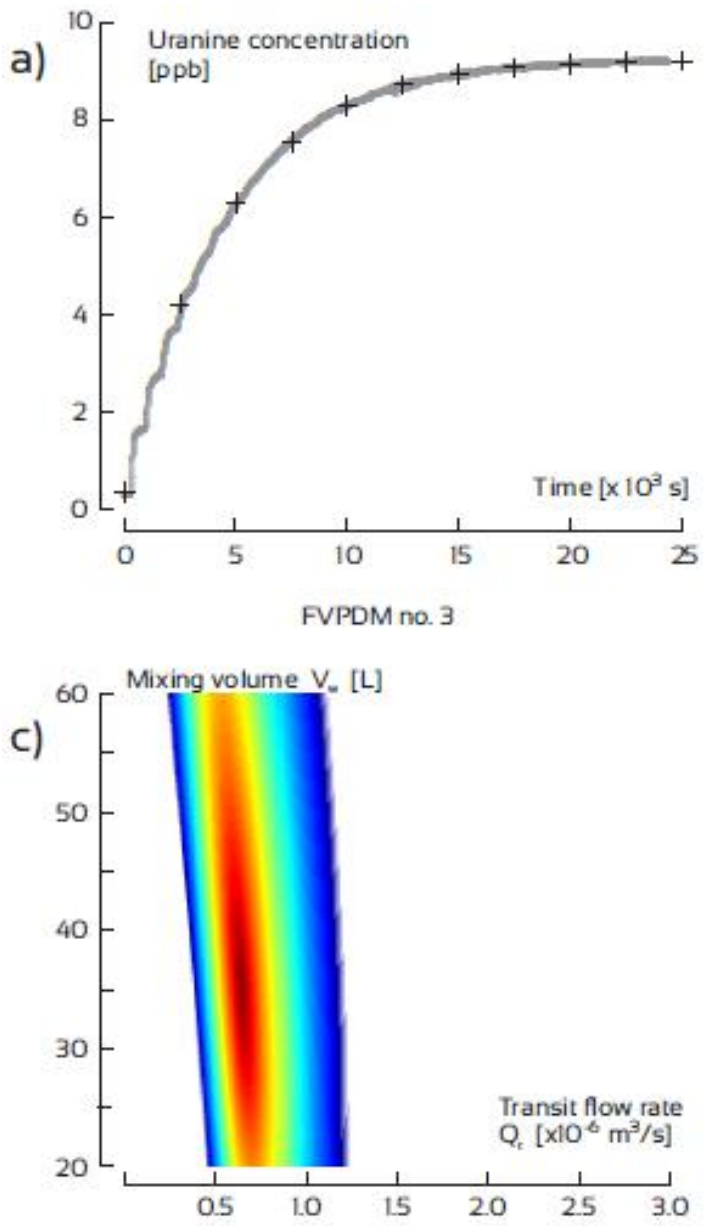

b) ${ }^{10}\left[+\begin{array}{l}\text { Uranine concentration } \\ {[\mathrm{ppb}]}\end{array}\right.$

+ Adjusted with

analytical solution

$\longrightarrow$ Experimental data

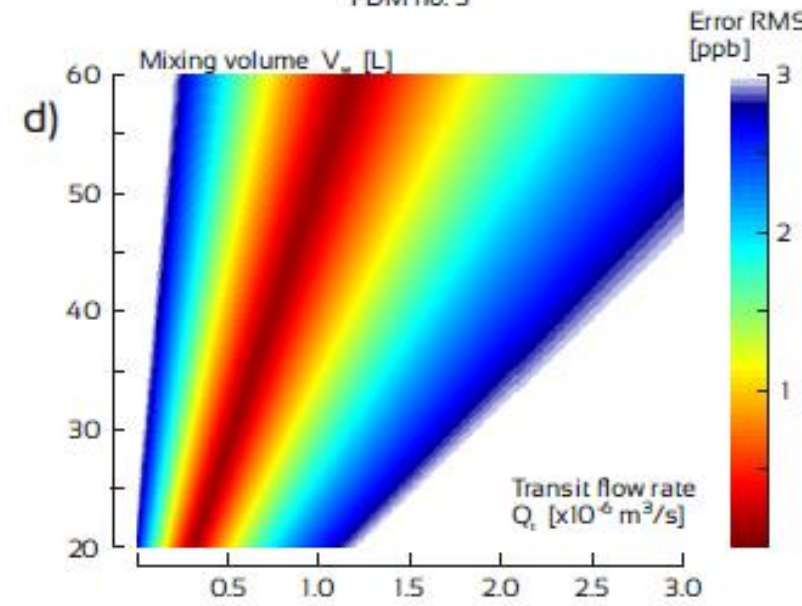

Figure 5 
FVPDM no. 3

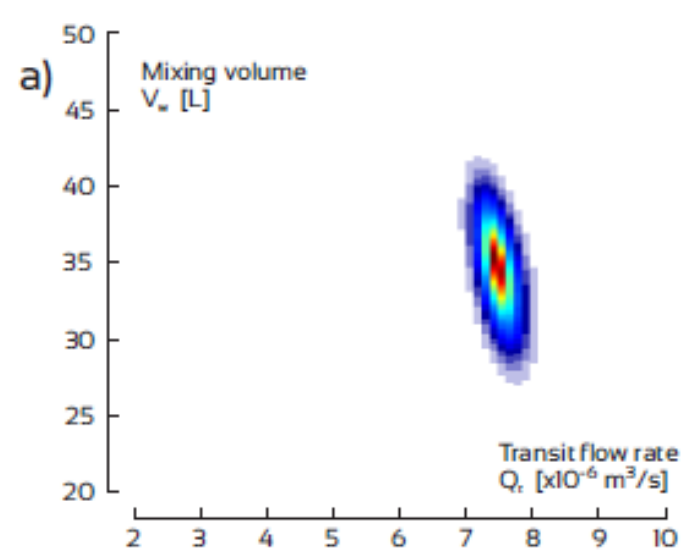

PDM no. 3

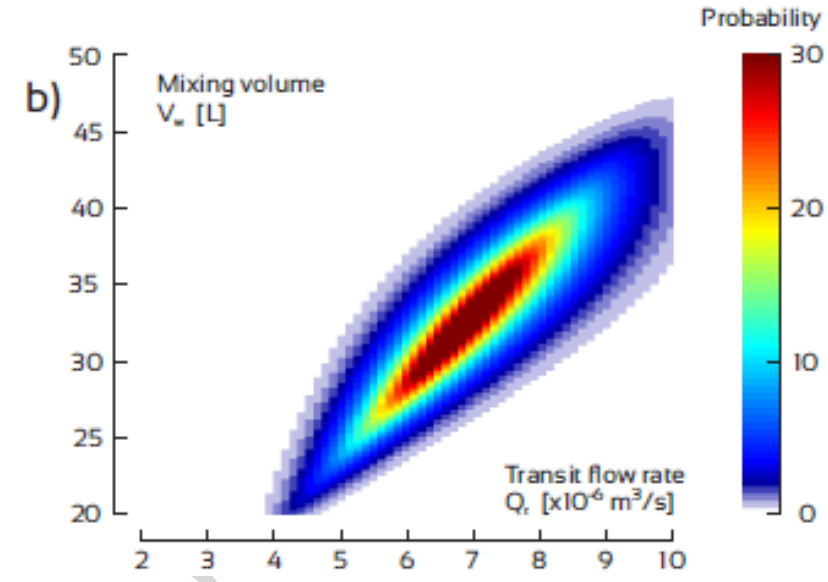

Figure 6 


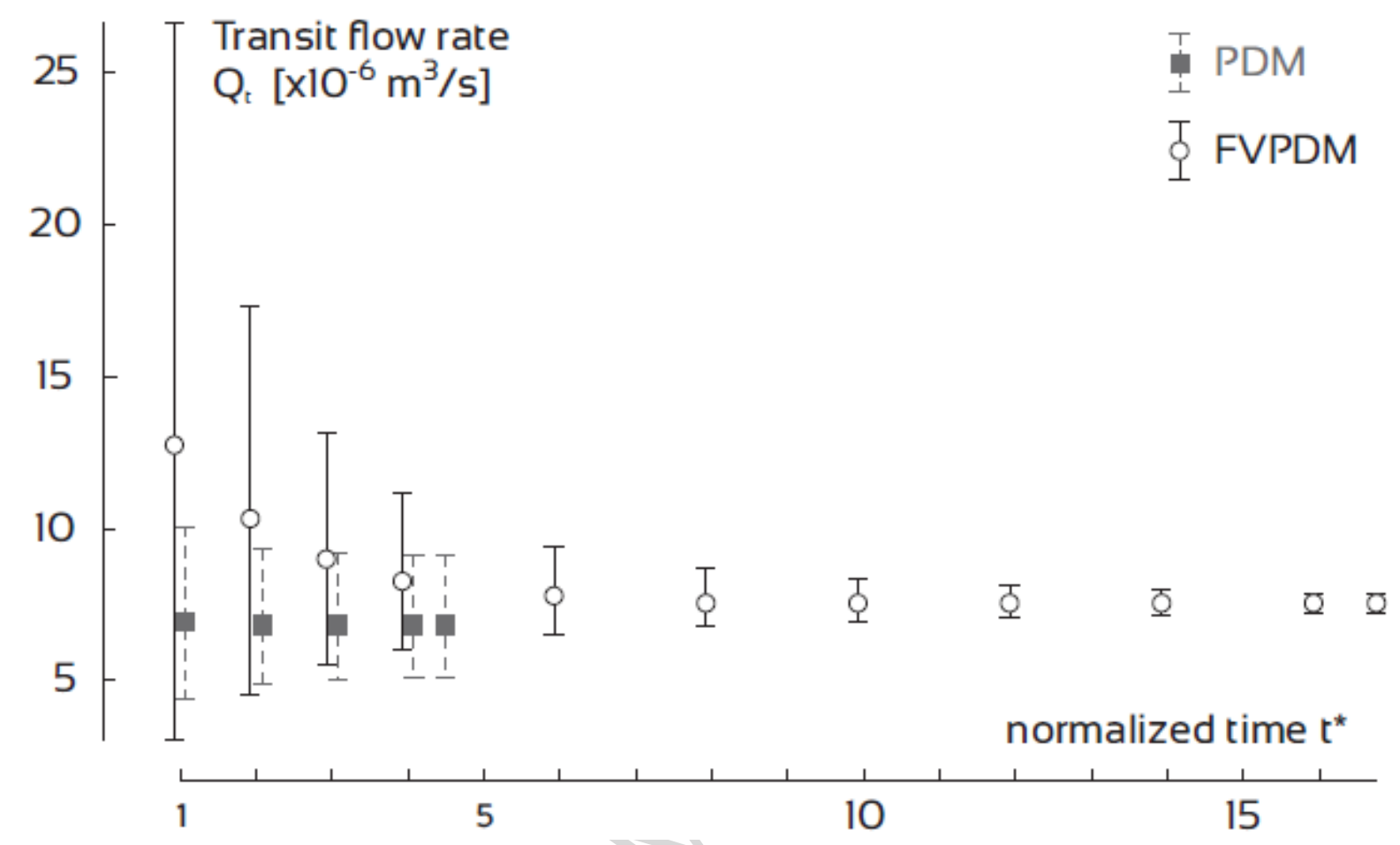

Figure 7 


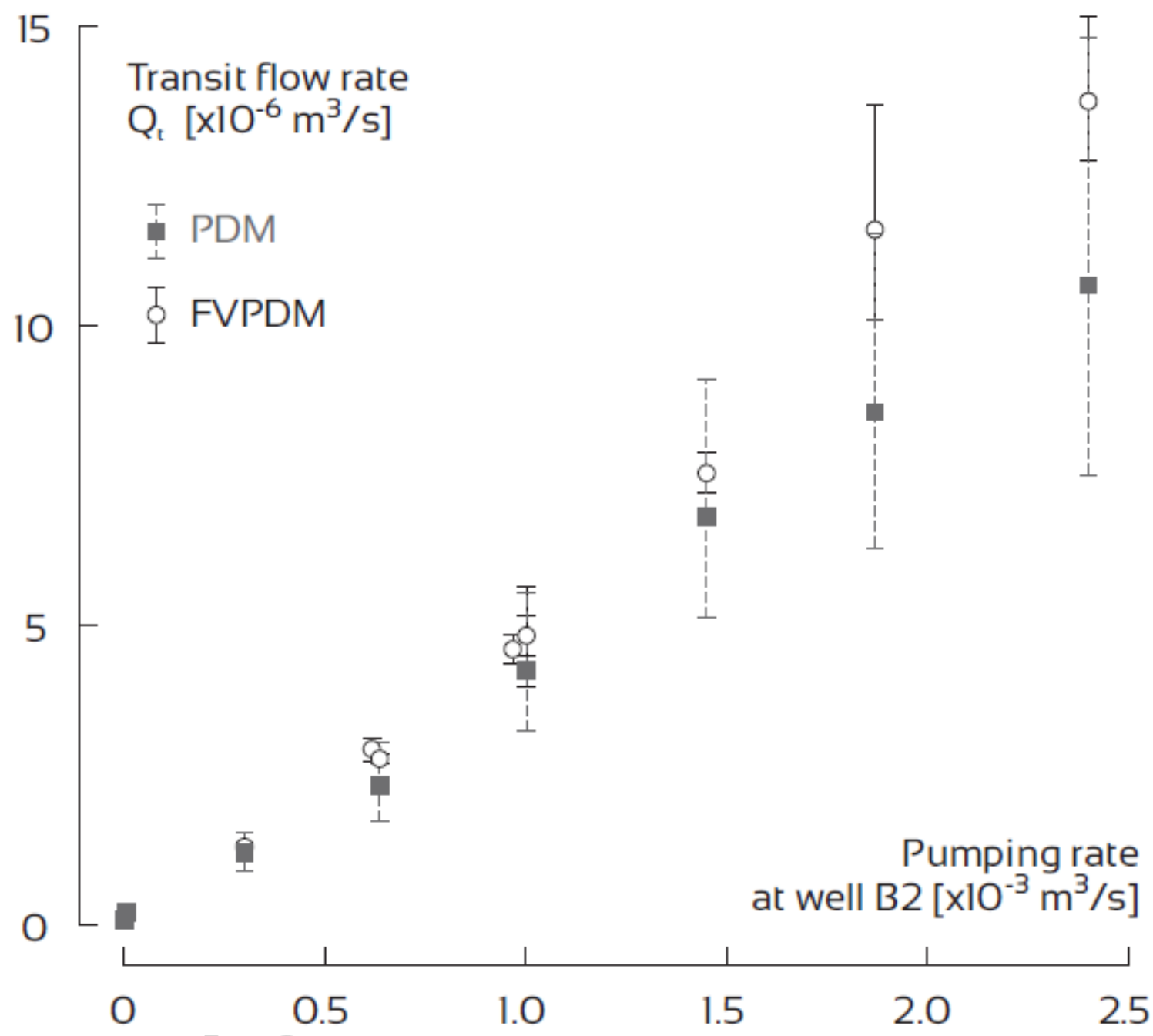

Figure 8 
Table 1

\begin{tabular}{|l|r|r|r|r|}
\hline Id & $\begin{array}{r}\text { Duration } \\
{[\mathrm{h}]}\end{array}$ & $\begin{array}{r}\mathrm{C}_{\mathrm{w}, 0 \text { in }} \\
\mathrm{B} 1-4 \\
{[\mathrm{ppb}]}\end{array}$ & $\begin{array}{r}\mathrm{Q}_{\text {in }} \text { in B1-4 } \\
{\left[\times 10^{-7} \mathrm{~m}^{3} \mathrm{~s}\right]}\end{array}$ & $\begin{array}{r}\mathrm{Q}_{\text {pump }} \text { in B2 } \\
{\left[\times 10-3 \mathrm{~m}^{3} \mathrm{~s}\right]}\end{array}$ \\
\hline FVPDM 1 & 4.02 & 0 & 3.5 & 2.39 \\
\hline PDM 1 & 0.88 & 5 & 0 & 2.39 \\
\hline FVPDM 2 & 2.35 & 0.2 & 3.5 & 1.86 \\
\hline PDM 2 & 2.28 & 6.1 & 0 & 1.86 \\
\hline FVPDM 3 & 6.70 & 0.3 & 3.5 & 1.46 \\
\hline PDM 3 & 1.67 & 9.2 & 0 & 1.46 \\
\hline FVPDM 4 & 3.39 & 1.4 & 3.5 & 1.00 \\
\hline FVPDM 5 & 2.83 & 12.5 & 3.5 & 0 \\
\hline PDM 4 & 1.88 & 31.4 & 0 & 0 \\
\hline PDM 5 & 2.24 & 30.3 & 0 & 1.00 \\
\hline FVPDM 6 & 3.15 & 10.2 & 3.5 & 1.00 \\
\hline FVPDM 7 & 8.67 & 14.1 & 3.5 & 0.63 \\
\hline FVPDM 8 & 7.84 & 23.2 & 3.5 & 0 \\
\hline PDM 6 & 5.93 & 68.0 & 0 & 0 \\
\hline PDM 7 & 2.45 & 64.9 & 0 & 0.63 \\
\hline FVPDM 9 & 28.01 & 2.4 & 3.5 & 0.31 \\
\hline FVPDM 10 & 8.72 & 45.1 & 3.5 & 0.62 \\
\hline PDM 8 & 2.10 & 23.5 & 0 & 0.29 \\
\hline
\end{tabular}


Table 2

\begin{tabular}{|l|l|l|l|l|l|l|l|l|}
\hline & \multicolumn{9}{l}{} & \multicolumn{2}{l|}{$\mathrm{V}_{\mathrm{w}}[\mathrm{L}]$} \\
\hline & Adjusted & $\mathrm{P} 05$ & $\mathrm{P} 95$ & P95-P05 & Adjusted & $\mathrm{P} 05$ & $\mathrm{P} 95$ & P95-P05 \\
\hline FVPDM 3 & 7.55 & 7.19 & 7.89 & 0.70 & 34.0 & 29.2 & 38.0 & 8.8 \\
\hline PDM 3 & 6.82 & 5.11 & 9.12 & 4.01 & 32.2 & 25.3 & 41.2 & 15.9 \\
\hline
\end{tabular}


Table 3

\begin{tabular}{|c|c|c|c|c|c|c|c|c|}
\hline \multirow[b]{2}{*}{ Id } & \multicolumn{5}{|c|}{ Data } & \multicolumn{3}{|c|}{ Results } \\
\hline & $\begin{array}{r}\text { Duration } \\
{[\mathrm{h}]}\end{array}$ & $\begin{array}{r}Q_{\text {pump }} \text { in } \\
B 2 \\
{\left[\times 10^{-3}\right.} \\
\left.\mathrm{m}^{3} / \mathrm{s}\right]\end{array}$ & $\begin{array}{r}\text { Drawdown } \\
\text { B2 }[\mathrm{m}]\end{array}$ & $\begin{array}{r}\text { Drawdown } \\
\mathrm{B} 1[\mathrm{~m}]\end{array}$ & $\begin{array}{r}\text { Duration/ } \mathrm{t}_{\mathrm{c}} \\
{[-]}\end{array}$ & $\begin{array}{r}Q_{t}\left[\times 10^{-6}\right. \\
\left.m^{3} / s\right]\end{array}$ & $\mathrm{V}_{\mathrm{w}}[\mathrm{L}]$ & $v\left[\times 10^{-3} \mathrm{~m} / \mathrm{s}\right]$ \\
\hline FVPDM 1 & 4.02 & 2.39 & 1.89 & 0.88 & 1.35 & $13.80 \pm 1.21$ & $32.9 \pm 5.5$ & $38.33 \pm 3.36$ \\
\hline PDM 1 & 0.88 & 2.39 & 1.89 & 0.88 & & $10.69 \pm 3.66$ & $32.5 \pm 7.9$ & $29.69 \pm 10.17$ \\
\hline FVPDM 2 & 2.35 & 1.86 & 1.30 & 0.60 & 0.64 & $11.6 \pm 1.80$ & $34.5 \pm 6.5$ & $32.22 \pm 5$ \\
\hline PDM 2 & 2.28 & 1.86 & 1.30 & 0.60 & & $8.56 \pm 2.63$ & $32.4 \pm 7.9$ & $23.78 \pm 7.31$ \\
\hline FVPDM 3 & 6.7 & 1.46 & 0.98 & 0.44 & 1.22 & $7.55 \pm 0.35$ & $34.0 \pm 4.4$ & $20.97 \pm 0.97$ \\
\hline PDM 3 & 1.67 & 1.46 & 0.98 & 0.44 & & $6.82 \pm 2.00$ & $32.2 \pm 7.9$ & $18.94 \pm 5.56$ \\
\hline FVPDM 4 & 3.39 & 1.00 & 0.62 & 0.31 & 0.48 & $4.83 \pm 0.83$ & $28.8 \pm 5.4$ & $13.42 \pm 2.31$ \\
\hline PDM 5 & 2.24 & 1.00 & 0.68 & 0.37 & & $4.25 \pm 1.16$ & $32.4 \pm 7.9$ & $11.81 \pm 3.22$ \\
\hline FVPDM 6 & 3.15 & 1.00 & 0.68 & 0.37 & 0.43 & $4.60 \pm 0.23$ & $28.2 \pm 6.4$ & $12.78 \pm 0.64$ \\
\hline FVPDM 7 & 8.67 & 0.63 & 0.36 & 0.17 & 0.67 & $2.78 \pm 0.08$ & $31.7 \pm 4.4$ & $7.72 \pm 0.22$ \\
\hline PDM 7 & 2.45 & 0.63 & 0.41 & 0.21 & & $2.33 \pm 0.66$ & $32.5 \pm 7.9$ & $6.47 \pm 1.83$ \\
\hline FVPDM 10 & 8.72 & 0.62 & 0.38 & 0.17 & 0.64 & $2.93 \pm 0.17$ & $34.8 \pm 6.0$ & $8.14 \pm 0.47$ \\
\hline FVPDM 9 & 28.01 & 0.31 & 0.13 & 0.03 & 1.09 & $1.32 \pm 0.04$ & $33.5 \pm 2.5$ & $3.67 \pm 0.11$ \\
\hline PDM 8 & 2.1 & 0.29 & 0.17 & 0.06 & & $1.20 \pm 0.32$ & $32.7 \pm 7.9$ & $3.33 \pm 0.89$ \\
\hline FVPDM 5 & 2.83 & 0 & 0.04 & 0.02 & 0.03 & * & 27.0 & * \\
\hline PDM 4 & 1.88 & 0 & 0.04 & 0.02 & & $0.22 \pm 0.09$ & $32.5 \pm 10.2$ & $0.61 \pm 0.25$ \\
\hline FVPDM 8 & 7.84 & 0 & 0.06 & 0.02 & 0.07 & * & 32.0 & * \\
\hline PDM 6 & 5.93 & 0 & 0.06 & 0.02 & & $0.07 \pm 0.02$ & $32.7 \pm 7.9$ & $0.19 \pm 0.06$ \\
\hline
\end{tabular}




\section{Abstract}

Measurement of groundwater fluxes is the basis of all hydrogeological study, from hydraulics characterization to the most advanced reactive transport modelling. Usual groundwater fluxes estimation with Darcy's law may lead to cumulated errors on spatial variability, especially in fractured aquifers where local direct measurement of groundwater fluxes becomes necessary.

In the present study, both classical Point Dilution Method (PDM) and Finite Volume Point Dilution Method (FVPDM) are compared on the fractured crystalline aquifer of Ploemeur, France. The manipulation includes the first use of the FVPDM in a fractured aquifer using a double packer. This configuration limits the vertical extend of the tested zone to target a precise fracture zone of the aquifer. The result of this experiment is a continuous monitoring of groundwater fluxes that lasted for more than 4 days.

Measurements of groundwater flow rate in the fracture $\left(Q_{t}\right)$ by PDM provide good estimates only if the mixing volume $\left(V_{w}\right)$ (volume of water in which the tracer is mixed) is precisely known. Conversely, the FVPDM allows for an independent estimation of $V_{w}$ and $Q_{t}$, leading to better precision in case of complex experimental setup such as the one used. The precision of a PDM does not rely on the duration of the experiment while a FVPDM may require long experimental duration to guarantees a good precision.

Classical PDM should then be used for rapid estimation of groundwater flux using simple experimental setup. On the other hand, the FVPDM is a more precise method that has a great potential for development but may require longer duration experiment to achieve a good precision if the groundwater fluxes investigated are low and/or the mixing volume is large. 


\section{Research highlights}

- Two single well techniques are compared in a fractured aquifer

- First FVPDM using a double packer setup and in a fractured aquifer

- A full length FVPDM is more precise at estimating groundwater fluxes than a PDM

- The precision of a PDM fully relies on external estimation of the mixing volume 